\section{Loyalitas Kreativitas \\ Aldi Masyarakat Kreatif}

P-ISSN 2722-2101, E-ISSN 2722-4201

Program Studi Ekonomi Manajemen Universitas Pamulang

Jurnal LOKABMAS Kreatif Vol.01,No.02 Juli 2020, Hal. 5-10

Email:jurnalkreatif.manajemen@gmail.com

\title{
MENINGKATKAN BONAFIDITAS LAPORAN KEUANGAN UMKM SCALE UP TANGERANG SELATAN MELALUI SISTEM INFORMASI APLIKASI PENCATATAN INFORMASI KEUANGAN (SI-APIK)
}

\author{
Aris Sanulika, Julian Maradina, Suciati Muanifah \\ Dosen Ekonomi Fakultas Ekonomi Universitas Pamulang
}

Emaildosen01236@unpam.ac.id, dosen01245@unpam.ac.id,dosen02242@unpam.ac.id

\begin{abstract}
ABSTRAK
Pengabdian kepada masyarakat dapat diartikan sebagai respon akademik masyarakat kampus atas kebutuhan, tantangan, atau persoalan yang dihadapi oleh masyarakat, baik secara langsung maupun tidak langsung. Tujuan umum dari kegiatan pengabdian kepada masyarakat ini adalah membantu UMKM dalam mengatasi persoalan-persoalan pencatatan laporan keuangan. Adapun bentuk kegiatan dalam pelaksanaan pengabdian kepada masyarakat dengan tema akuntansi keuangan. Dengan para pengajar dan narasumber yang dilibatkan adalah para Dosen Program Studi Akuntansi dari Universitas Pamulang.

Hasil Pelaksanaan PKM yang dilakukan tanggal 24-28 Februari 2020 adalah menambah ilmu mereka di bidang akuntansi, terutang tentang pencatatan keuangan, para peserta kelompok ikan hias di desa Jampang sangat antusias dengan materi yang mereka dapatkan dari dosen-dosen akuntansi Universitas Pamulang, Para peserta dapat langsung mempraktekan pembukuan melaui aplikasi SIAPIK, Respon para peserta sangat baik dan senang karena sangat terbantu dalam pembelajaran tentang pencatatan keuangan. Pentingnya pengelolaan aspek keuangan usaha membuat para UMKM sadar bahwa pendapatan harus di putar agar usaha terusmaju. Saran yang disampaikan adalah kegiatan PKM kedepannya agar digalakan dan dibuat semenarik mungkin agar dapat menjaring lebih banyak lagi peserta UMKM di Tangerang Selatan, perluasan jangkauan cakupan wilayah materi bisa lebih diperluas sehingga peserta dapat memperoleh wawasan lebih banyak.
\end{abstract}

Kata kunci : Laporan Keuangan, SI-APIK, UMKM

\section{ABSTRAC}

Community service can be interpreted as an academic response from the campus community to challenges, or debates that are questioned by the community, both directly and indirectly. General objectives of community service activities Share the form with community service activities with the theme of financial accounting. The instructors and resource persons involved were Accounting Study Program Lecturers from Pamulang University.

The results of the implementation of the PKM conducted on 24-28 February 2020 were adding to their knowledge in the field of accounting, owing to financial records, the participants of the ornamental fish group in Jampang were very enthusiastic about the material they got from accounting lecturers at Pamulang University, the participants could directly practiced bookkeeping through the application SI-APIK, the response of the participants was very good and happy because it was very helpful in learning about financial records. The Importance of the Articles of Association of Business Makes MSMEs Aware That Money Must Be Played So that Businesses Go Forward The suggestion given was that in the future PKM activities should be promoted and made as interesting as possible to 
attract more MSME participants in South Tangerang, to be able to obtain more information about areas of material that could be studied by the participants so that they could be learned more.

Keywords: Financial Reports, SI-APIK, UMKM

\section{PENDAHULUAN}

Meski skala bisnis yang ditargetkan oleh UMKM tidak sebesar perusahaan kelas kakap, banyak orang yang nyaman berbisnis dalam level UMKM karena keunggulan yang ditawarkan pada bisnis UMKM dan keunggulan tersebut sulit didapatkan di level bisnis raksasa.

Salah satu keunggulan UMKM yang utama adalah kemudahan dalam mengadopsi inovasi dalam bisnis, terutama dalam bidang teknologi. Adopsi teknologi terbaru menjadi lebih mudah dilakukan untuk meningkatkan pertumbuhan bisnis UMKM karena UMKM tidak memiliki birokrasi yang berbelit dan sistem yang rumit.

Pada zaman globalisasi seperti sekarang ini, semua orang harus berlomba-lomba menjalankan UMKM dan meraih peluang bisnis yang ada. Untuk itu, diperlukan pengaturan keuangan bisnis yang baik untuk menunjang keberlangsungannya.

Bisnis yang baik tentunya harus diiringi dengan pembukuan finansial yang memadai agar pengeluaran dan pemasukan usaha dapat dimonitor secara akurat. Selain itu, pembukuan yang benar juga akan bermanfaat dalam membantu mengambil keputusan dan pertanggungjawaban bisnis. Dengan demikian, pembukuan yang benar juga merupakan hal yang sangat penting dalam memulai bisnis baru agar Anda dapat lebih menjamin keberlangsungan usaha. Pastikan selalu fokus saat sedang melakukan pembukuan untuk meminimalisi kekeliruan yang dapat membawa dampak fatal bagi pertumbuhan usaha. Perlu diingat juga kalau pembukuan hanyalah langkah awal untuk memproses akuntansi. Pada akhirnya, seluruh data yang sudah Anda kumpulkan harus diterjemahkan melalui proses akuntansi agar kondisi finansial usaha terlihat dengan jelas. Kombinasi pembukuan yang benar dan proses akuntansi adalah kunci untuk mengambil keputusan-keputusan jitu berbisnis.
Dengan mempertimbangkan latar belakang yang telah dijelaskan diatas kami berinisiatif untuk UMKM memiliki potensi yang sangat bagus yang harus dikembangkan, namun karena keterbatasan pengetahuan dan kurangnya pembinaan, usaha mereka belum memiliki sistem pebukuan yang baik. Berikut permasalaan yang dihadapi UMKM.

1. Masalah manajemen keuangan yang mereka rasa masih bingung

2. Masih belum paham tentang tata cara pembukuan yang baik dan benar.

3. Masih belum bisa melihat perkembangan pergerakan arus kasnya serta untung dan ruginya.

\section{TUJUAN PELAKSANAAN}

Tujuan umum dari kegiatan pengabdian kepada masyarakat ini adalah membantu UMKM secara khusus tujuan kegiatan pengabdian kepada masyarakat ini adalah:

1. Mensosialisasikan manajemen keuangan yang dirasa masih membingungkan

2. Membantu untuk memberikan kemudahan dalam tata cara pembukuan kepada UMKM.

3. Membantu memberikan informasi dalam penyusunan laporan keuangan agar UMKM dapat melihat perkembangan pergerakan arus kasnya serta untung dan ruginya.

\section{TINJAUAN PUSTAKA}

Pelatihan, pendampingan dan kebijakan untuk para UMKM harus menuju ke arah pengentasan masalah kebelumpahaman pengelolaan keuangan usaha. Dengan ini kami akan memberikan pelatian serta pemdampingan dalam pencatatan laporan keuangan muda dan simpel bagi para pemula, karena sekrang sudah era digital jadi pelaporannya kami kemas dalam suatu aplikasi SI-APIK. Beragam fitur dan kemudahan yang ditawarkan dalam aplikasi ini berikut beberapa fitur yang dapat dimanafatkan

\section{RUMUSAN MASALAH}




\section{Loyalitas Kreativitas \\ Aldi Masyarakat Kreatif}

P-ISSN 2722-2101, E-ISSN 2722-4201

Program Studi Ekonomi Manajemen Universitas Pamulang

Jurnal LOKABMAS Kreatif Vol.01,No.02 Juli 2020, Hal. 5-10

Email:jurnalkreatif.manajemen@gmail.com
Aplikasi akuntansi (pencatatan informasi keuangan/SI APIK) bagi usaha mikro dan kecil. Aplikasi pembukuan ini dapat mencatat jenis transaksi sederhana bagi usaha perorangan (usaha mikro) maupun juga usaha kecil. Perbedaan pencatan usaha mikro dibandingkan usaha kecil terletak pada kompleksitas pencatatan dan laporan keuangan. Usaha Mikro hanya mencatat dan melaporkan sumber dan penggunaan dana, sementara usaha kecil menengah (UKM) menyusun laporan yang lebih lengkap seperti laporan laba rugi, arus kas dan neraca.

Standard pencatatan tersebut mengacu kepada standard yang disusun oleh Bank Indonesia bersama Ikatan Akuntan Indonesia (IAI). Jadi, sistem pencatatannya sudah baku, diakui dan dapat diterima oleh perbankan maupun lembaga keuangan lainnya. Dengan demikian, laporan-laporan dari aplikasi ini akan dijadikan landasan bagi pengajuan pembiayaan (kredit) kepada perbankan maupun lembaga keuangan lainnya.

Pencatatan dalam aplikasi ini mencatat double entry (debit-kredit) dengan sistem input single entry atau menurut jenis-jenis transaksinya, bukan menginput berdasarkan akun-akun yang merumitkan. Pengguna tidak perlu memilih transaksi debit dan lawan transaksi kreditnya. Pengguna hanya perlu mengkategorikan apakah transaksi yang akan dicatat termasuk penerimaan atau pengeluaran

Aplikasi akuntansi bagi UKM ini dapat menyajikan laporan keuangan seperti Neraca, Laba Rugi, Arus Kas dan Rincian Pos Keuangan. Di samping itu, PTK juga dilengkapi dengan laporan kinerja keuangan mencakup solvabilitas, likuiditas, profitabilitas, perputaran modal kerja, kinerja operasional dan repayment capacity dengan penjelasan yang ringkas dan mudah dipahami

\section{METODE}

Kegiatan pengabdian kepada masyarakat ini mengusung tema "Meningkatkan Bonafiditas Laporan Keuangan UMKM Scale Up Tangerang Selatan Melalui Sistem Informasi Aplikasi Pencatatan Informasi Keuangan (SI-APIK)."
Kegiatan Pengabdian Kepada Masyarakat dilakukan melalui penyuluhan dan presentasi materi tentang Sistem Informasi Aplikasi Pencatatan Informasi Keuangan (SI-APIK) yang di paparkan oleh para Dosen Prodi Akuntansi dari Universitas Pamulang.

Pelatihan, pendampingan dan kebijakan untuk para UMKM harus menuju ke arah pengentasan masalah kebelumpahaman pengelolaan keuangan usaha. Berikut tahapan yang dapat diterapkan :

a. Unduh dan daftarkan usaha dengan aplikasi SI-APIK

Karena sekarang sudah era digital jadi pelaporannya dikemas dalam suatu aplikasi SIAPIK. Beragam fitur dan kemudahan yang ditawarkan dalam aplikasi ini.

b. Pemisahan hasil usaha

Belum adanya pemisahan keuangan antara uang usaha dan uang kebutuhan hidup harian. Fenomena ini seringkali terjadi karena pelaku usaha menganggap usahanya masih kecil dan bersifat usaha keluarga. Uang hasil usaha ini juga yang mereka pakai untuk memenuhi kebutuhan sehari-hari. Padahal, usaha memerlukan akumulasi modal yang diambil dari keuntungan, guna memastikan usaha itu semakin besar. Kebutuhan keuangan harian memang boleh dipenuhi dari keuntungan usaha yang tercipta. Namun harus punya batas yang jelas. Yakni sebesar laba bersih dikurangi target keuntungan yang ditargetkan kembali masuk sebagai penambah modal. Sirkulasinya boleh saja harian, mingguan, ataupun bulanan.

c. Mengitung keuntungan

Para pembudidaya ikan tidak tahu secara pasti seberapa besar keuntungan usaha mereka. Berapa persen laba bersih mereka. Kalimat yang penting bisa makan adalah jawaban yang paling sering didengar ketika bicara soal keuntungan kepada pelaku usaha. Sikap yang asal ini yang menyebabkan mereka tidak kunjung profesional. Padahal salah satu indikator bagus tidaknya prospek dan perjalanan usaha, salah satunya terletak pada kewajaran tingkat keuntungan sebuah komoditi. Artinya, jika keuntungan usaha kita jauh dari nilai wajar keuntungan sebuah produk, penetapan ulang harga jual atau 


\section{Loyalitas Kreativitas \\ Aldi Masyarakat Kreatif}

P-ISSN 2722-2101, E-ISSN 2722-4201

Program Studi Ekonomi Manajemen Universitas Pamulang

Jurnal LOKABMAS Kreatif Vol.01,No.02 Juli 2020, Hal. 5-10

Email:jurnalkreatif.manajemen@gmail.com negosiasi harga perolehan bahan baku mungkin harus segera dilakukan.

d. Membuat laporan keuangan sederhana

Masih banyak pelaku usaha yang merasa tidak perlu menyusun laporan keuangan sesederhana apapun sebagai bahan analisa kegiatan usahanya. Alasan mereka, yang penting uang hasil penjualan hari ini bisa untuk modal lagi keesokan harinya. Padahal tidak bisa begitu. Selamanya usaha tersebut tidak akan berkembang jika hal-hal keuangan yang kecil tidak mulai diperhatikan sejak awal.

\section{e. Strategi keuangan}

Kacaunya manajemen keuangan ketika pelaku usaha sudah terlibat dalam hubungan hutang dagang atau hutang ke lembaga keuangan. Keberadaan hutang menyuratkan sebuah kewajiban yang sifatnya fixed secara besaran dan periodik aspek waktu pemenuhannya. Ketidakmampuan mengelola kewajiban ini akan lebih parah dari sekadar tidak bisa memisahkan uang usaha dengan uang keperluan hidup sehari-hari. Nasib pengusaha yang mengalami ketidak berdayaan memenuhi kewajiban hutangnya akan lebih sengsara. Padahal ketidakmampuan itu belum tentu berasal dari tidak profitnya usaha atau tidak terpenuhinya margin keuntungan minimal, namun lebih karena ketidakprofesionalan mereka mengelola cash in dan cash out usaha. Sangat disayangkan kalau ini yang terjadi. Maka, kami memprioritaskan aspek edukasi dan pemahaman manajemen keuangan kepada UMKM.

\section{HASIL DAN PEMBAHASAN}

Kegiatan pengabdian pada masyarakat ini dilaksanakan di Auditorium UNPAM. Kegiatan ini diikuti oleh 3 peserta dari UMKM

Pada tanggal 24-28 Februari 2020 pada pukul 09.00 sampai 14.00 WIB. Secara umum kegiatan ini berjalan dengan lancar dan antusiasme yang tinggi para UMKM untuk mengikuti kegiatan tersebut. karena mereka ingin mengetahui bagaimana cara mengatur keuangan dan pencatatan keuangan dengan baik dan benar.
Antusia para kelompok tani dalam sosialisasi dapat dilihat pada gambar berikut ini:

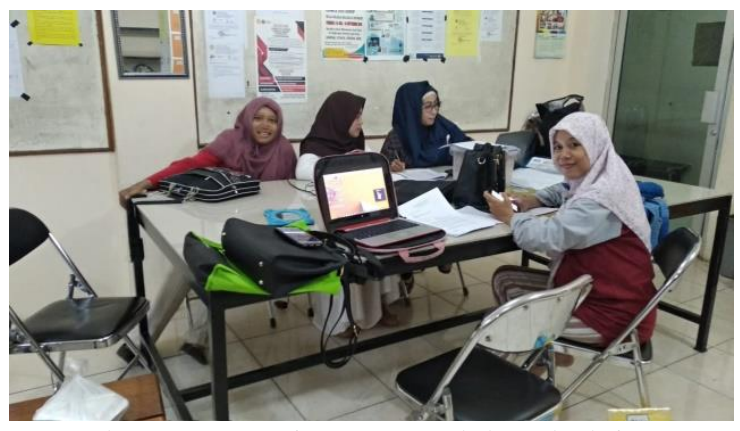

Gambar 1. Antusia peserta dalam belajar SIAPIK

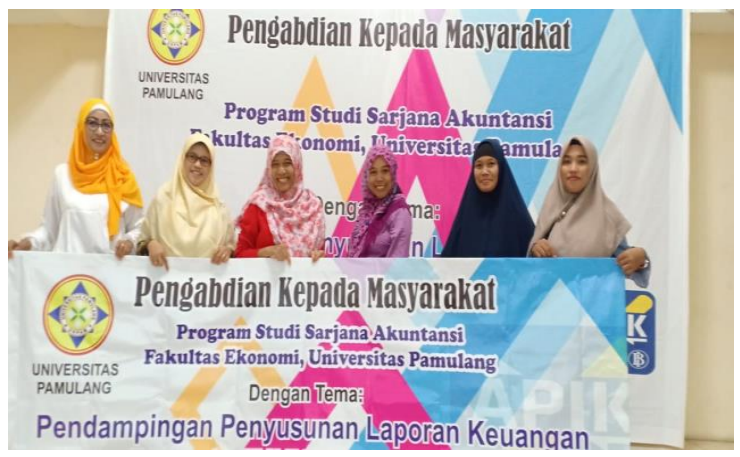

Gambar 2. Antusia peserta dalam belajar SIAPIK

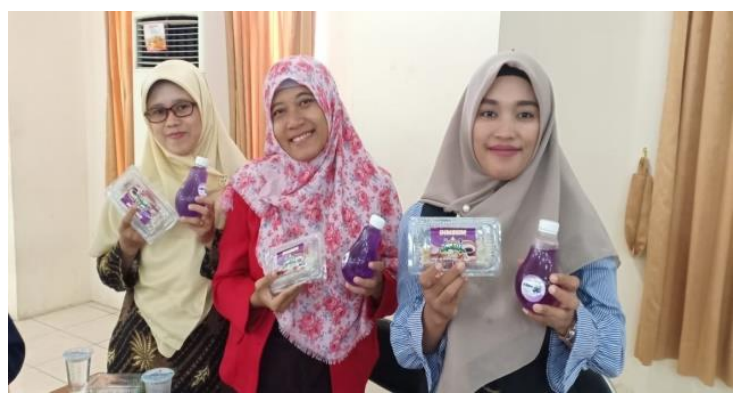

Gambar 3. Produk UMKM

Materi yang disampaikan pada saat sosialisasi tentang pentingnya pencatatan laporan keuangan dengan tema "Meningkatkan Bonafiditas Laporan Keuangan UMKM Scale Up Tangerang Selatan Melalui Sistem Informasi Aplikasi Pencatatan Informasi Keuangan (SI-APIK).” yaitu: Hasil pelaksanaan PKM yang dilakukan pada tanggal 


\section{Loyalitas Kreativitas \\ Aldi Masyarakat Kreatif}

P-ISSN 2722-2101, E-ISSN 2722-4201

Program Studi Ekonomi Manajemen Universitas Pamulang

Jurnal LOKABMAS Kreatif Vol.01,No.02 Juli 2020, Hal. 5-10

Email:jurnalkreatif.manajemen@gmail.com
24-28 Februari 2020 dengan peserta adalah Pelaku UMKM menunjukkan bahwa:

1. Kegiatan yang dilaksanakan untuk UMKM adalah kegiatan menambah ilmu mereka di bidang akuntansi, terutama tentang pencatatan keuangan.

2. Para peserta UMKM sangat antusias dengan materi yang mereka dapatkan dari dosendosen akuntansi Universitas Pamulang, karena mereka merasa keuangan harian tidak jelas dan selalu merasa kurang karena tiba-tiba uang sudah habis tidak tahu untuk memenuhi kebutuhan apa saja.

3. Dengan keterbatasan waktu yang ada, para peserta UMKM bisa mendapatkan materi langsung dari dosen akuntansi Universitas Pamulang secara langsung dan mempraktekkannya.

4. Respon para peserta UMKM, mereka sangat terbantu dalam pembelajaran tentang pencatatan keuangan.

\section{KESIMPULAN}

Setiap kegiatan ekonomi tentunya harus diiringi dengan pembukuan finansial yang memadai agar pengeluaran dan pemasukan usaha dapat dimonitor secara akurat. Selain itu, pembukuan yang benar juga akan bermanfaat dalam membantu mengambil keputusan dan pertanggungjawaban bisnis. Begitupun dengan UMKM tentang pencatatan pengeluaran rutin harian, UMKM mempunyai andil besar serta peran penting dalam memanage keuangan usahanya. Oleh karena itu UMKM bertanggung jawab untuk membuat pembukuan bagaimana arus uang keluar dan masuk setiap harinya, apasaja kebutuhan untuk perputaran usaha.

\section{SARAN}

Beberapa saran yang disampaikan adalah sebagai berikut:

1. Kegiatan serupa ke depannya agar digalakkan dan dibuat semenarik mungkin agar dapat menjaring lebih banyak lagi UMKM.

2. Perluasan jangkauan cakupan wilayah serta materi bisa lebih diperluas lagi sehingga para peserta diharapkan dapat memperoleh wawasan yang lebih banyak

\section{DAFTAR PUSTAKA}

https://play.google.com/store/apps/details?id=c om.ptk\&hl=in diakses pada tanggal $(9$ april 2020)

Dina Amalia.2019.Perbedaan Usaha Mikro, Kecil, dan Menengah https://www.jurnal.id/id/blog/2017perbedaan-umkm-perkembangannya-di indonesia/ diakses pada tanggal (9 april 2020)

Pasaribu, V. L. D., Agrasadya, A., Shabrina, N., \& Krisnaldy, K. (2020). MENJADI ENTERPRENEUR MUDA YANG MEMILIKI JIWA LEADERSHIP UNTUK MENGHADAPI MASA DEPAN. Abdi Laksana, 1(1)

Pasaribu, V. L. D., Elburdah, R. P., Sudarso, E., \& Fauziah, G. (2020). PENGGUNAAN MANAJEMEN WAKTU TERHADAP PENINGKATAN PRESTASI BELAJAR DI SMP ARAISIYAH. Jurnal ABDIMAS, 1(1)

Pasaribu, V. L. D., Susanti, F., \& Hartuti, E. T. K. (2019). MEMOTIVASI SISWA DAN SISWI SMK LETRIS INDONESIA DI DALAM MENENTUKAN PILIHAN UNTUK MELANJUTKAN PENDIDIKAN ATAU BEKERJA SETELAH LULUS SEKOLAH. Jurnal Pengabdian Dharma Laksana, 1(2), 161-172.

Pasaribu, V. L. D., Oktrima, B., Prabowo, B., Arianto, N., \& Haryoko, U. B. (2020). PROGAM PENDAMPINGAN DAN

PENYELENGGARAAN PENDIDIKAN ANAK PADA USIA DINI TERHADAP PRESTASI BELAJAR DILINGKUNGAN RT 020 RW 009. KEL GIRI PENI. KEC WATES. YOGYAKARTA. JURNAL LOKABMAS KREATIF, 1(1), 71-75.

Pasaribu, V. L. D., Sulaiman, S., Sutiman, S., Thaharudin, T., \& Purnomo, B. Y. (2020). PENGENALAN LETAK POSYANDU TERDEKAT DIKELURAHAN PISANGAN 


\section{Loyalitas Kreativitas \\ Aldi Masyarakat Kreatif}

\section{P-ISSN 2722-2101, E-ISSN 2722-4201}

Program Studi Ekonomi Manajemen Universitas Pamulang Jurnal LOKABMAS Kreatif Vol.01,No.02 Juli 2020, Hal. 5-10 Email:jurnalkreatif.manajemen@gmail.com
DENGAN MANAJEMEN PEMASARAN REVOLUSI 4.0 UNTUK MENINGKATKAN PENGETAHUAN MASYARAKAT LETAK DAN FUNGSI POSYANDU TERDEKAT PADA KELURAHAN PISANGAN. DEDIKASI PKM, 1(1), 105-110.

Pasaribu, V. L. D., \& Krisnaldy, K. (2019). Manajemen Risiko dan Asuransi.

\section{DOKUMENTASI KEGIATAN}
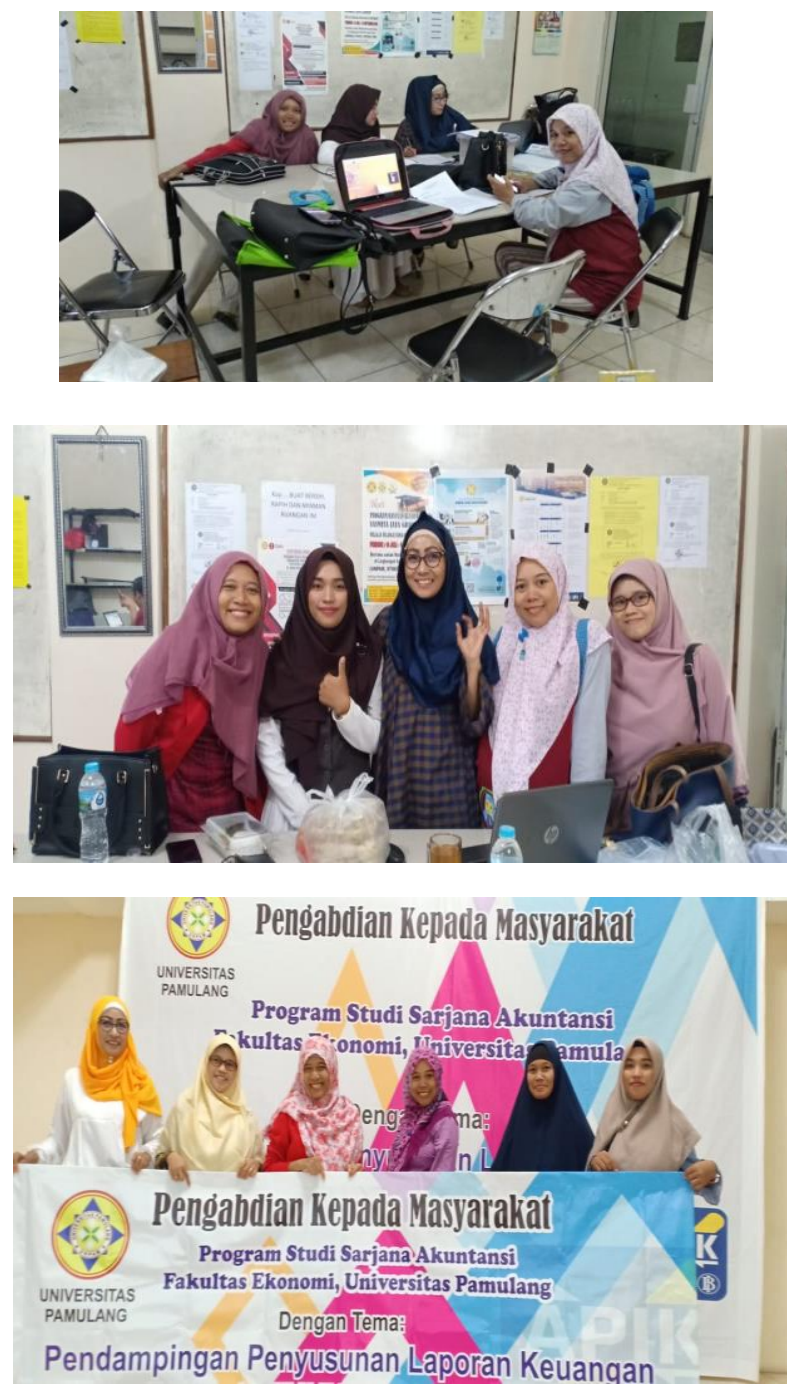

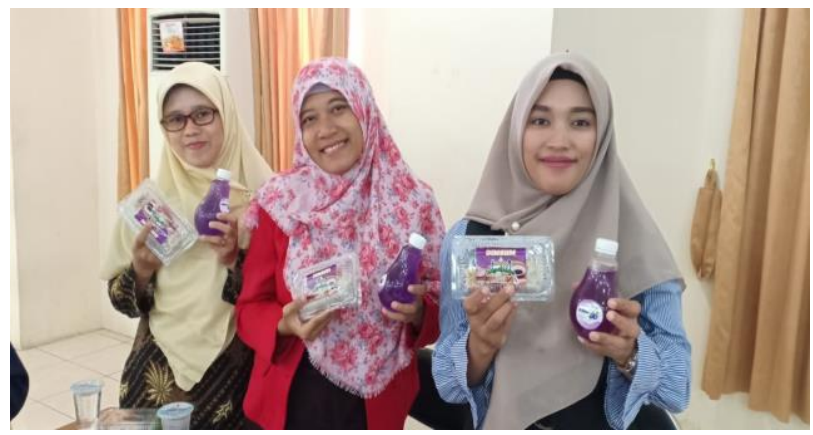

